\title{
Üç farklı universal adeziv sistemin dentine makaslama bağlanma dayanımlarının karşılaştırıması*
}

\author{
Gülnur Işıl Türk, Emine Kara ${ }^{1}$
}

Selcuk Dental Journal, 2015; 2: 51-57

Basvuru Tarihi: 14 Mayıs 2015 Yayına Kabul Tarihi: 26 Mayıs 2015

\section{Comparansion of shear bond strength of three universal adhesive} system

Background: The aim of this study is to compare shear bond strengths of three universal adhesives (3M ESPE Single Bond Universal, G-aenial Bond, (GC, Japan), Clearfil Universal Bond, (Kuraray, Japan) to dentin.

Methods: 36 freshly extracted noncarious molar were selected for this study. Occlusal flat dentin surfaces were exposed by cuttuing occlusal enamel and by $600,800,1000,1200$ grid paper, standard smear layer was obtained. The teeth were randomly divided into three groups $(n=12)$. Group 1: 3M Single Bond Universal, Group 2: G-aenial Bond (GC, Japan) Group 3: Clearfil Universal Bond (Kuraray, Japan). Adhesives were applied to dentine according to the manufacturers' instructions. The resin composite (Tetric EvoCeram, Ivoclar, Vivadent, Sweeden) of each adhesive system was applied on the bonded dentin surface using an application apparatus (Ultradent Products Inc.). The materials were light-cured according to the manufacturers' instructions by a LED. After 24 hour storage in distilled water at room temperature, the shear bond test was carried out using a universal testing machine with a cross head speed $0.5 \mathrm{~mm} / \mathrm{min}$. The data were analyzed with One Way ANOVA and post-hoc Tukey tests. Fracture analyzes of all samples were done using a light microscope.

Results: Statistical analysis showed no significant differences in shear bond strengths between three groups $(p>0.05)$. 3M Single Bond Universal $(14,44 \pm 3,38 \mathrm{mPa})$, G-aenial Bond (12,32 \pm 3,75 $\mathrm{mPa})$, Clearfil Universal Bond $(11,30 \pm 2,92 \mathrm{mPa})$. Clearfil Universal Bond showed the lowest shear bond strength to dentin.

Conclusion: The three tested universal adhesive systems showed similar shear bond strength to dentin. These results should be supported by clinical practice.

\section{KEY WORDS}

Dentin bonding agents, shear bond strength, universal bonding systems
Restoratif materyal ve diş sert dokuları arasında sıkı bir bağlantı sağlamak adeziv diş hekimliğinin amacını oluşturmaktadır (Baier 1992). Ağız ortamında yeterli adezyonun sağlanabilmesi için adeziv materyalin; diş dokularını yeterince ıslatması, diş ile rezin arayüzeyindeki stres miktarı azaltması ve bu arayüzün ağız ortamı etkilerine karşı bozulmadan stabil kalabilmesini sağlaması gerekmektedir (Eick ve ark 1991).

Rezin-diş dokularının bağlantısını sağlayan rezin monomerler olan dental adezivler (Perdigao 2007) hidrofobik ve hidrofilik gruplardan oluşmaktadır. Ayrıca kimyasal yapılarında başlatıcılar, durdurucular veya stabilize ediciler ile çözücüler ve bazı durumlarda inorganik doldurucular yer almaktadır (Van Landuyt ve ark 2007).

Dental adezyon teknolojisinde etch\&rinse ve self-etch sistemler olmak üzere iki farklı strateji yer almaktadır. Bunlardan aseton bazlı olan etch\&rinse sistemlerin 'wet bonding' tekniğine uygun olarak kullanılması önerilmektedir (Reis ve ark 2007, Tay ve ark 1996). Fakat dentini nemli bırakıp mineyi kurutmak ve dentinin yeterince ıslak ya da kuru olduğunu belirlemek pratikte pek mümkün olamamaktadır (Tay ve ark 1996, Pereira ve ark 2001). Kollajen fibriller arasına adeziv rezinin yayılmasını azaltan dentin nemliliği sorunu ise günümüzde self-etch adeziv sistemlerle ortadan kaldırılmıştır. Ancak

\footnotetext{
*Yüzüncü Yll Üniversitesi Diş Hekimliği Fakültesi Uluslararası Sempozyumu’nda 4-7 Eylül 2014 tarihinde poster olarak tebliğ edilmiştir.

${ }^{1}$ Yüzüncü Yıl Üniversitesi Diş Hekimliği Fakültesi Restoratif Diș Tedavisi Anabilim Dalı
} 
Ancak self-etch adezivler içinde bulunan asitler, fosforik asit kadar güçlü olmadıklarından minede daha düşük bağlanma oluşturmaktadır. Bu nedenle uzun dönemde restorasyon mine kenarlarından ayrılmaya başlamaktadır (Peumans ve ark 2010). Bu durumun engellenmesi amacıyla self-etch adezivlerin uygulanmasından önce kavitenin yalnızca mine kenarlarının selektif olarak asitlenmesi önerilmektedir (Erickson ve ark 2009). Ancak pratikte minenin asitlenmesi sırasında dentin de aside maruz kalabilmektedir. Son zamanlarda klinik olarak kullanım kolaylığı sağlayan tek aşamalı self-etch adezivlerin dezavantajlarını ortadan kaldırmaya yönelik çalışmalar sonucunda "Universal" veya "Multi mode" olarak isimlendirilen ürünler ortaya çıkarılmıştır (Hanabusa ve ark 2012). Bu ürünler hem self-etch, hem minenin seçici asitlenmesi, hem de etch\&rinse olarak kullanılabilmektedirler.

Bu çalışmanın amacı üç farklı universal bağlayıcı ajanın self-etch sistem olarak kullanımının dentin yüzeyindeki makaslama bağlanma dayanımı kuvvetlerini karşılaştırmaktır.

\section{GEREÇ ve YÖNTEM}

Çalışmamızda kullanılmak üzere son 6 ay içinde çekilmiş 36 adet sağlam gömülü 3 . molar diş seçildi ve okluzal mineleri su soğutması altında kesme bıçağı ile (Isomet, Buhler, Almanya) uzaklaştırıldı. Açığa çıkan dentin yüzeyinde 600, 800, 1000 ve 1200 gritlik zımparalar kullanılarak standart bir smear tabakası elde edildi. Dişler okluzal yüzeyleri açıkta kalacak şekilde akrile gömülerek ve 3 gruba ayrıldı $(n=12)$;

1.Grup: 3M Single Bond Universal (3M ESPE, Amerika),

2.Grup: G-aenial Bond (GC, Japonya),

3.Grup: Clearfil Universal Bond (Kuraray, Japonya).

Bağlayıcı ajanların üretici firmaların talimatlarına göre (Tablo-1) uygulanmasının ardından 10 sn LED ışık cihazıyla (3M ESPE Elipar Freelight II, Amerika) polimerize edildi. Ardından diş yüzeylerine plastik aparatlar vasıtasıyla (Ultradent, Amerika) (Resim-1) kompozit (Tetric EvoCeram A 3.5, Ivoclar, Vivadent, İsviçre) yerleştirildi ve LED ışık cihazı ile 40 sn polimerize edildi. 24 saat oda sıcaklığında distile suda bekletilen örnekler universal test cihazı ile (Shimadzu, Japonya) makaslama dayanımı testine $0.5 \mathrm{~mm} /$ dak hızla tabi tutuldu (Resim-2 ve Resim-3) ve elde edilen değerler mPa'a çevrildi. Kırılma yüzey analizleri Işık mikroskobunda x40 büyütmede (TM 505, Mitutoyo, Tokyo, Japonya) değerlendirildi. Çalışmanın istatistiksel analizlerinde one way Anowa ve Post Hoc Tukey testleri kullanıldı.
Tablo 1.

Kullanılan bağlayıcı ajanların içerikleri ve uygulama
talimatları

\begin{tabular}{|c|c|c|}
\hline $\begin{array}{l}\text { Kullanilan Bonding } \\
\text { Ajanlar }\end{array}$ & İçerik & Uygulama Talimatları \\
\hline $\begin{array}{l}\text { Single Bond } \\
\text { Universal ( } 3 \mathrm{M} \text {, } \\
\text { Amerika) }\end{array}$ & $\begin{array}{l}\text { 10-MDP, dimetakrilat } \\
\text { rezinler, HEMA, } \\
\text { metakrilatmodifiye } \\
\text { polialkenoik asit } \\
\text { kopolimeri, doldurucu, } \\
\text { etanol, su, initiatörler, silan }\end{array}$ & $\begin{array}{l}\text { Kaviteye } 20 \mathrm{sn} \\
\text { uygulanır. } 5 \mathrm{sn} \text { havayla } \\
\text { kurutulur. } 10 \mathrm{sn} \text { ışıkla } \\
\text { polimerize edilir. }\end{array}$ \\
\hline $\begin{array}{l}\text { G-aenial Bond } \\
\text { (GC, Japonya) }\end{array}$ & $\begin{array}{l}\text { 4-MET, fosforik asit ester } \\
\text { monomeri, dimetakrilat, } \\
\text { su, aseton, nano-silika } \\
\text { doldurucu ve fotoinitiatör }\end{array}$ & $\begin{array}{l}\text { Kaviteye tek tabaka } \\
\text { sürülür. } 10 \text { sn beklenir. } \\
5 \text { sn güçlü hava sıkıır. } \\
10 \text { sn ışıkla polimerize } \\
\text { edilir. }\end{array}$ \\
\hline $\begin{array}{l}\text { Clearfil Universal } \\
\text { Bond (Kuraray, } \\
\text { Japonya) }\end{array}$ & $\begin{array}{l}\text { 10-MDP, Bisfenol A } \\
\text { diglisidmetakrilat, } \\
\text { hidroksietil metakrilat, } \\
\text { etanol, hidrofilik alifatik } \\
\text { metakrilat, koloidal silika, } \\
\text { kamforokinon, silan, } \\
\text { akselatör, iniatör, su }\end{array}$ & $\begin{array}{l}\text { Kaviteye } 10 \mathrm{sn} \\
\text { uygulanır. } 5 \mathrm{sn} \text { havayla } \\
\text { kurutulur. } 10 \mathrm{sn} \text { ışıkla } \\
\text { polimerize edilir. }\end{array}$ \\
\hline
\end{tabular}

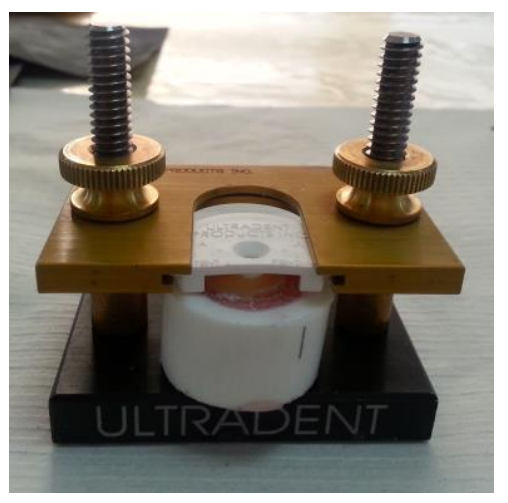

Resim 1.

Dentin yüzeylerine kompozit

yerleştirilmesini sağlayan aparat

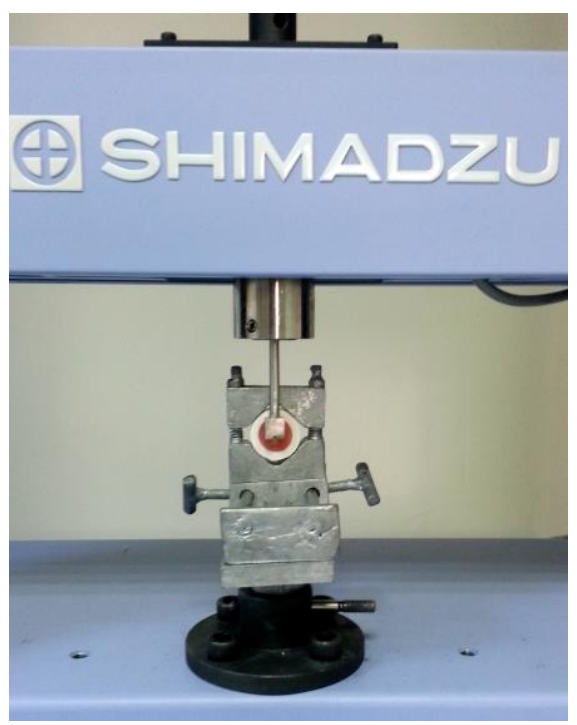

Resim 2.

Örneklerin universal test cihazına yerleştirilmesi 


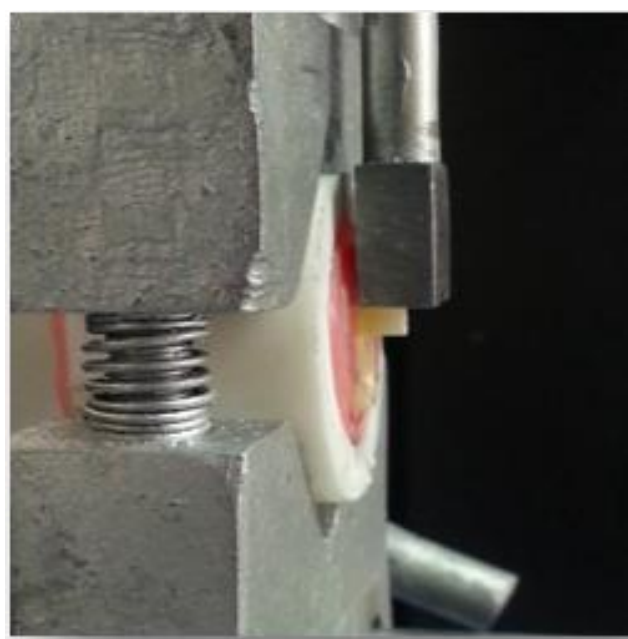

Resim 3.

Universal test cihazı ile shear testi

\section{BULGULAR}

İstatistiksel analizler sonucunda elde edilen değerlere bakıldığında $3 \mathrm{M}$ Single Bond Universalin bağlanma dayanımı ortalamasının 14,44 $\pm 3,38 \mathrm{mPa}$, G-aenial Bond'un bağlanma dayanımı ortalamasının $12,32 \pm 3,75 \mathrm{mPa}$, Clearfil Universal Bond'un bağlanma dayanımı ortalamasının ise $11,30 \pm 2,92 \mathrm{mPa}$ olduğu gözlendi (Tablo-2 ve Grafik-1). Gruplar arasında istatistiksel olarak anlamlı bir fark bulunamadı $(p>0.05)$. Fakat bağlanma dayanımlarına bakıldığında 3M Single Bond Universal'in diğer bonding sistemlere göre sayısal değer olarak daha yüksek ortalama bağlanma dayanımı gösterdiği bulundu. Örneklerin kırılma yüzey analizleri de Tablo3 'te gösterilmektedir. Koheziv kırılma hiçbir örnekte gözlenmezken adeziv kırılmanın daha fazla olduğu görüldü. Başarısızlık tiplerinin incelenmesinde esas alınan kriterler aşağıdaki şekilde belirlenmiştir;

1. Restoratif materyalin \%20'sinden daha az dentin yüzeyinde kalmışsa adeziv başarısızlık

2. Restoratif materyalin \%80'inden fazlası dentin yüzeyinde kalmışsa koheziv başarısızık

3. Dentin yüzeyinde koheziv başarısızlıktan daha az ama adeziv başarısızlıktan daha fazla restoratif mateyal kalmışsa mix (adeziv+koheziv) başarısızlık (Woronko ve ark 1996).
Tablo 2.

\section{Grupların ortalama bağlantı değerleri ve standart sapmaları}

\begin{tabular}{|c|c|c|c|}
\hline Gruplar & $\begin{array}{l}\text { Örnek } \\
\text { sayısı }\end{array}$ & $\begin{array}{c}\text { Ortalama } \\
\text { değer } \\
(\mathrm{mPa})\end{array}$ & $\begin{array}{c}\text { Standart } \\
\text { Sapma }\end{array}$ \\
\hline $\begin{array}{l}\text { Single Bond } \\
\text { Universal }\end{array}$ & $n=12$ & 14,44 & $\pm 3,38$ \\
\hline G-aenial Bond & $n=12$ & 12,32 & $\pm 3,75$ \\
\hline $\begin{array}{l}\text { Clearfil } \\
\text { Universal Bond }\end{array}$ & $n=12$ & 11,3 & $\pm 2,92$ \\
\hline
\end{tabular}

\section{Ortalama bağlantı değeri (mPa)}

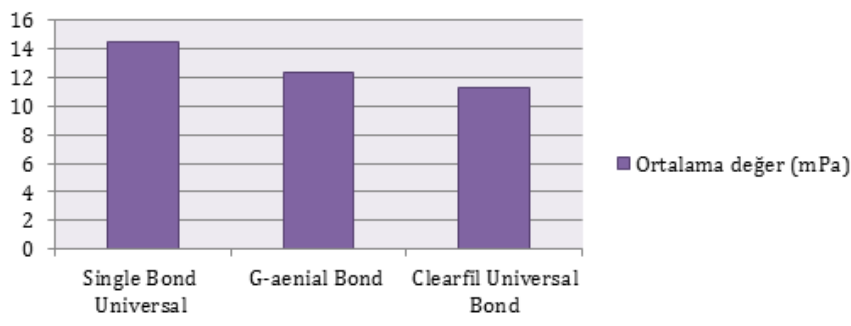

Grafik 1.

Grupların ortalama bağlantı değerleri ve standart sapmaları grafiği

Tablo 3.

\section{Grupların kırılma tipleri}

\begin{tabular}{lccc|}
\hline Gruplar & Adeziv & Koheziv & Mix \\
Single Bond Universal & 11 & - & 1 \\
\hline G-aenial Bond & 10 & - & 2 \\
\hline Clearfil Universal Bond & 9 & - & 3 \\
\hline
\end{tabular}

\section{TARTIŞMA}

Kuraray Clearfil SE Bond'un 10-MDP monomeri ile olan patent anlaşmasının sona ermesi ile, kimyasal bağlanma potansiyeline sahip olan yeni bir adeziv sistem ailesi ortaya çıkmıştır (Sezinando 2014). Uygulama prosedürlerindeki farklııklarından dolayı bu sistemlere 'universal veya multimode adeziv sistemler' adı verilmiştir. Üretici firmaların talimatlarına göre universal adeziv sistemler etch\&rinse, selfetch ve minenin selektif asitlenmesi şeklinde uygulanabilmektedirler (Perdigao ve Loguercio 2014).

Bazı universal adezivlerin içeriğinde bulunan 10-MDP monomerinin dentinde elde edilen total etch ve self etch bağlantı dayanımı değerlerini değiştirdiği çeşitli çalışmalarla gösterilmiştir (Peumans ve ark 2005, Van Meerbeek ve ark 2011, Yoshida ve ark 2012). Bu farkın sebebinin ise monomerin kollajen fibriller içindeki rezidüel apatitle kimyasal bağ oluşturmasından kaynaklandığı belirtilmektedir (Munoz ve 
ark 2013, Marchesi ve ark 2014). 10-MDP monomeri kollajen fibril çevresinde, rezidüel hidroksiapatitteki kalsiyum iyonlarıyla iyonik bağ kurarak hidrolitik bozulmaya karşı kararlı 10-MDP-Ca tuzlarını oluşturmaktadır (Van Meerbeek ve ark 2011). Bu durum bağlantının stabilitesinin ve ömrünün mevcut bağlantı dayanımına göre artmasına sebep olabilmektedir (Van Meerbeek ve ark 2011, Yoshida ve ark 2000). Yoshida ve ark (2012) yaptıkları çalışmada 10-MDP içeren self-etch adezivlerin diş-adeziv arayüzeyinde kendinden birleşen nanotabakalar oluşturduğunu bildirmişlerdir. Bu durum, yüksek bağlantı değerlerinin sebebi olarak görülmektedir. Ayrıca, nano tabakalar boyunca stabil MDP-Ca tuzları birikimi laboratuvar ve klinik çalışmalarla doğrulanan (Peumans ve ark 2010, Toledano ve ark 2007, Feitosa ve ark 2012) yüksek bağlantı değerlerini açıklayabilmektedir (Yoshida ve ark 2012, Yoshihara ve ark 2010).

10-MDP'den başka phenyl-P ve 4-MET gibi başka fonksiyonel asidik monomerler de geliştirilmiştir (Van Landuyt ve ark 2007, Yoshihara ve ark 2010). Ancak bunların hiçbirinin 10-MDP'den daha yüksek bağlantı değerlerine sahip olmadığı görülmüştür. Ayrıca bu monomerlerin kalsiyum tuzları çözünmeye karşı daha dayanıksız ve hidrolitik olarak daha kararsız olduğundan bağlanma dayanımlarının daha düşük olduğu görülmüştür (Tay ve Pashley 2001, Peumans ve ark 2005, Van Landuyt ve ark 2008). Yoshida ve ark (2004) yaptıkları çalışmada sadece kimyasal bağlantıyı etkili bir şekilde artırması değil, sudaki çözünürlüklerinin de diğer fonksiyonel monomer olan 4-MET ve phenyl-P'den daha stabil olduğunu göstermektedir.

Universal adeziv sistemlerin kullanım modları (etch\&rinse, self-etch, selektif etch) dışında içeriklerindeki farklılıklar da bağlantı değerlerini etkilemektedir. G-aenial Bond'un yapısında fosforik asit ester monomeri, 4-MET, dimetakrilat, su, aseton, nanosilika doldurucu ve fotoinitiatör bulunmaktadır ve $\mathrm{pH}^{\prime}$ 1.5'tir. HEMA içermemesi nedeniyle ağız içinde daha uzun süre stabil kalabilmesi beklenmektedir (Takahashi ve ark 2011). 3M Single Bond Universal yapısında MDP, dimetakrilat rezinler, polialkenoik asit kopolimeri, doldurucu, etanol, su, initiatör ve silan bulunmaktadır ve pH'ı 2.7'dir. İçerdiği polialkenoik asit kopolimeri ve MDP sayesinde iyi bir bağlanma performansı göstermektedir (Van Meerbeek ve ark 2011, Perdigao ve ark 2013). Clearfil Universal Bond kompozisyonunda MDP, Bis-GMA, HEMA, kamforokinon, hidrofilik alifatik dimetakrilat, silan, silika, akselatör içermektedir. pH'ı 2.3'tür. Chen ve ark (2015) Prime\&Bond Elect, Scotchbond Universal, All-Bond Universal, Clearfil Universal Bond and Futurabond U'u etch\&rinse ve selfetch modda dentin yüzeyine uygulayarak mikrotensile bağlanma dayanımı testi ve TEM ile yüzey analizi yaptıkları çalışmalarında, söz konusu adezivlerin her iki modda kullanımının da dentin yüzeyine mikrotensile bağlanma dayanımını değiştirmediğini bildirmişlerdir. Hibrit tabaka kalınlığının ise etch\&rinse modda daha fazla olduğunu belirtmişlerdir.

Dentinin ekspoze olmuş kollajeni adeziv tarafından tam olarak örtülenemezse, kollajen fibriller zamanla hidrolitik bozulmaya maruz kalarak hibrit tabaka içinde boşluklar oluşmasına sebep olurlar (Sezinando 2014). Tek aşama self-etch adezivlerde olduğu gibi, hidrofobik rezin tabakası içeren universal adeziv sistemlerin uzun dönemde bağlantı değerlerini artırarak nanosızıntıyı azaltabileceği düşünülmektedir (Perdigao ve ark 2014a, Munoz ve ark 2014).

Perdigao ve ark (2014b) 3M Single Bond Universal'i etch\&rinse, self-etch, selektif etch modda uyguladıkları ve 18 ay boyunca takip ettikleri klinik çalışmalarında yalnızca marjinal adaptasyonda fark bulunduğu sonucuna varmışlardır. 3M Single Bond Universal'in pH'ı 2.7 olduğu için minede fosforik asitin oluşturduğu etkiye ulaşamadığı ve bu nedenle minenin selektif asitlenmesinin ön gereklilik olduğu belirtilmiştir (Perdigao ve ark 2012).

Peşkersoy ve ark (2013) 3M Single Bond kullanarak dört farklı kompozit rezin ile restore ettikleri Black V kavitelerinde oluşan mikrosızıntıyı inceledikleri çalışmalarında, tüm gruplarda servikal kavite kenarlarında okluzal kavite kenarlarına göre daha fazla mikrosızıntı oluştuğunu bildirmişlerdir.

Marchesi ve ark (2014) in vitro ortamda 3M Single Bond Universal ve Prime\&Bond NT'yi dentin yüzeyine self-etch, etch\&rinse modda nemli dentine, etch\&rinse modda kuru dentine uygulamışlar ve 24 saat, 6 ay ve 1 yıl bekleme süresinin sonunda mikrotensile bağlanma dayanımı, nanosızıntı ve MMP aktivitesi testleri uygulamışlardır. 1 yıl sonunda self-etch modda uygulanan her iki adeziv materyal de daha yüksek mikrotensile bağlanma dayanımı gösterirken; Prime\&Bond NT, 3M Single Bond Universal'a göre daha yüksek mikrotensile dayanımı göstermiştir. Gruplar arasındaki en az nanosızıntı 3M Single Bond Universal'in self-etch modda kullanıldığı grupta görülmüştür. Bütün gruplarda MMP aktivitesi izlenmiştir.

Barutçugil ve ark (2013a) \%35 fosforik asit ve dört farklı güç parametrelerinde $\mathrm{Er}, \mathrm{Cr}$ :YSGG lazer kullanarak hazırladıkları dentin yüzeyi örneklerine 3M Single Bond Universal uygulayarak makaslama bağlanma dayanımını inceledikleri çalışmalarında; fosforik asit uygulanan grupta bağlantı değerlerinde artış gözlenirken Er,Cr:YSGG lazer uygulanan bütün gruplarda 
bağlantı değerlerinin azaldığını bildirmişlerdir. Bu azalmanın sebebinin erbiyum lazerlerin hidroksiapatit kristallerine etki ederken aynı zamanda kollajen fibril ağlarına zarar vermesinden kaynaklandığını düşünmüşlerdir.

Barutçugil ve ark (2013b) 3M Single Bond Universal (etch\&rinse ve self-etch mod), All-Bond Universal (etch\&rinse ve self-etch mod), Adper Single Bond 2, Clearfil SE Bond, Futurabond M kullanarak dentin yüzeyinde makaslama bağlanma dayanımı testi yapmışlardır. Her iki universal adeziv sistem için de fosforik asit uygulamasının bağlantı değerlerini artırdığını ve self etch uygulamalar arasında en düşük bağlantı değerlerinin Futurabond M'de görüldüğünü bildirmişlerdir.

Hanabusa ve ark (2012) G-aenial Bond'u mine yüzeyine etch\&rinse ve self-etch modda; dentin yüzeyine self-etch, etch\&rinse modda hem kuru hem de nemli dentine uygulayarak mikrotensile bağlanma testi yapmışlardır ve dentin-rezin arayüzeyini TEM ile incelemişlerdir. Mikrotensile bağlanma testi sonucunda minede etch\&rinse modun daha yüksek bağlanma değeri gösterdiğini; dentinde ise self-etch modda kuru dentine bağlanmanın diğer deney gruplarından daha başarılı olduğu bildirilmiştir. TEM analizi sonucunda dentin yüzeyine etch\&rinse uygulanan grubun biodegradasyona daha yatkın olduğu belirtilmiştir.

Munoz ve ark (2013) Clearfil SE Bond ve Adper Single Bond kontrol grubu olarak; Peak Universal Bond, 3M Single Bond Universal, All Bond Universal'in self-etch ve etch\&rinse modda kullanımının mikrotensile bağlanma dayanımına ve nanosızıntıya etkilerini inceledikleri çalışmalarında, mikrotensile bağlanma dayanımı testi sonuçlarına göre yalnızca Peak Universal Bond'un hem etch\&rinse hem de self-etch modda kullanımın kontrol grupları ile benzer olduğu gözlenmiştir. Gruplar nanosızıntı açısından incelendiğinde ise 3M Single Bond Universal ve All Bond Universal gruplarının hem self-etch hem etch\&rinse modda kullanımlarının kontrol gruplarıyla aralarında fark bulunamamıştır.

Dönmez ve arkadaşlarının iki farklı multimode adeziv sistemi hem etch\&rinse hem de self-etch modda dentine uygulayarak termal siklusa maruz bıraktıkları ve mikrotensile bağlantı dayanımlarını inceledikleri çalışmalarında; en yüksek bağlanma değerlerinin etch\&rinse modda ve termal siklus uygulanmayan gruplarda gözlendiği sonucuna varmışlardır. Ayrıca All-Bond Universal adezivin termal siklus uygulamasından $3 \mathrm{M}$ Single Bond Universal'a göre daha fazla etkilenerek bağlantı değerlerinin düştüğünü belirmişlerdir (Dönmez ve ark 2015).

Mena-Serrano ve arkadaşlarının yaptıkları klinik çalışmada, 3M Single Bond Universal'i kullanarak selfetch, selektif etch veya etch\&rinse modda çürüksüz servikal lezyonları tedavi ettikten sonra klinik koşullarda 6 ay boyunca değerlendirmişler ve 6 ayın sonunda aralarında fark bulamadıklarını bildirmişlerdir (Mena-Serrano ve ark 2013).

Bizim çalışmamızda test edilen üç farklı universal adeziv sistemin istatistiksel olarak sağlam dentine aynı derecede makaslama bağlanma dayanımı gösterdiği ancak değerlere bakıldığında, 3M Single Bond Universal'in diğer bonding sistemlere göre daha yüksek bağlanma dayanımı gösterdiği bulunmuştur. Bunun sebebinin ajanların içeriklerinin benzerliğine ilaveten 3M Single Bond Universal'in içeriğinde bulunan polialkenoik asitin kopolimerinin bulunmasıyla rezidüel hidroksiapatitlerin yapısında bulunan $\mathrm{Ca}$ iyonlarıyla kimyasal bağlanmasından ileri geldiği düşünülmektedir.

Grupların kırılma tiplerinin de analiz edildiği bu çalışmada, ağırlıklı olarak adeziv tipte kırılmalar olduğu; sadece birkaç örnekte mix kırılma olduğu görülmüştür. Bu sonuçlar, daha önce yapılan çeşitli araştırmalarla paralellik göstermektedir (Asaka ve ark 2006, Pleffken ve ark 2011, Dönmez ve ark 2015).

\section{SONUÇ}

Bu çalışmanın sonucunda self-etch modda kullanılan üç farklı universal adeziv sistemin dentine olan bağlanma dayanımlarının benzer bulunması nedeniyle bu sistemlerin farklı modlarda kullanılarak in vitro ortamda test edilmesi gerektiğinin sonucuna varılmıştır. İlerleyen zamanda yapılan bu çalışmanın ayrıca uzun dönem bağlantısının da araştırıması gerekmektedir. 
Üç farklı universal adeziv sistemin dentine makaslama bağlanma dayanımlarının karşılaştrılması

Amaç: Çalışmanın amacı üç farklı universal dentin bağlayıcı ajanın self-etch modda kullanımının dentin yüzeyindeki makaslama bağlanma dayanımı kuvvetlerini araştırmaktır.

Gereç ve Yöntemler: Çalışmamızda kullanılmak üzere 36 adet sağlam molar diş seçildi ve okluzal mineleri uzaklaştırıldı. Açığa çıkan dentin yüzeyinde 600, 800, 1000 ve 1200 gritlik zımparalar kullanılarak standart bir smear tabakası elde edildi. Dişler okluzal yüzeyleri açıkta kalacak şekilde akrile gömüldü ve 3 gruba ayrıldı $(n=12) ; 1$. Grup: 3M Single Bond Universal (3M ESPE, Amerika), 2. Grup: G-aenial Bond (GC, Japonya), 3. Grup: Clearfil Universal Bond (Kuraray, Japonya). Bağlayıcı ajanların üretici firmaların talimatlarına göre uygulanmasının ardından ışıkla polimerize edilerek üzerlerine plastik aparatlar vasıtasıyla (Ultradent) kompozit (Tetric EvoCeram, Ivoclar, Vivadent, İsviçre) yerleştirildi. Bonding ve kompozit LED ışık cihazı ile polimerize edildi. 24 saat oda sıcaklığında distile suda bekletilen örnekler universal bir test cihazı ile makaslama dayanımı testine $0.5 \mathrm{~mm} / \mathrm{dak}$ hızla tabi tutuldu. Kırılma yüzey analizleri ışık mikroskobunda yapıldı. Elde edilen veriler one way Anowa ve Post Hoc Tukey testleri ile değerlendirildi.

Bulgular: İstatistiksel analizler sonucunda elde edilen değerler: 3M Single Bond Universal $(14,44 \pm 3,38 \mathrm{mPa})$, G-aenial $(12,32 \pm 3,75 \mathrm{mPa})$, Clearfil Universal Bond $(11,30 \pm 2,92 \mathrm{mPa})$. Gruplar arasında istatistiksel olarak anlamlı bir fark bulunamadı $(p>0.05)$.

Sonuç: Test edilen üç farklı universal adeziv sistem de sağlam dentine aynı derecede makaslama bağlanma dayanımı göstermiştir. $\mathrm{Bu}$ sonuçların klinik çalışmalarla da desteklenmesi gerekmektedir.

\section{ANAHTAR KELIMELER}

Dentin bonding ajanlar, shear bond dayanımı, universal bonding sistemler

\section{KAYNAKLAR}

Asaka Y, Yamaguchi K, Inage H, Takamizawa T, Kurokawa $\mathrm{H}$, Rikuta A, Kuroda T, Miyazaki M, 2006. Effect of thermal cycling on bond strengths of single-step self etch adhesives to bovine dentin. J Oral Sci, 48;63-9.

Baier RE, 1992. Principles of adhesion. Oper Dent, 5.1-9.

Barutçugil Ç, Barutçugil K, Kürklü D, Arslan H, 2013a. Farkli yüzey işlemleri uygulanmiş dentine universal bağlayici ajanin bağlanma dayaniminin incelenmesi. J Dent Fac Atatürk Uni, 21(3):324-30.

Barutçugil Ç, Barutçugil K, Kürklü D, Harorlı OT, 2013b. Güncel dentin bağlayıcı ajanların ve uygulama yöntemlerinin makaslama bağlanma dayanımlarının karşılaştırıması. İnönü Üniversitesi Sağlık Bilimleri Dergisi, 2:27-32.

Chen C, Niu LN, Xie H, Zhang ZY, Zhou LQ, Jiao K, Chen $\mathrm{JH}$, Pashley DH, Tay FR, 2015. Bonding of universal adhesives to dentine - Old wine in new bottles? J Dent, 43(5):525-36.

Dönmez N, Herguner Siso S, Usumez A, Bayrakçı I, 2015. Effect of thermal cycling on micro-tensile bond strength of composite restorations bonded with multimode adhesive. J Adhes Sci Technol, 8:731-39.

Eick JD, Cobb CM, Chapell RP, Spencer P, Robinson SJ, 1991. The dentinal surface: its influence on dentinal adhesion part I. Quintessence Int, 2:967-77.

Erickson RL, Barkmeier WW, Latta MA, 2009. The role of etching in bonding to enamel: A comparison of self-etching and etch-and-rinse adhesive systems. Dent Mater, 25:145967.

Feitosa VP, Leme AA, Sauro S, Correr-Sobrinho L, Watson TF, Sinhoreti MA, 2012. Hydrolytic degradation of the resindentin interface induced by the stimulated pulpal pressure, direct and indirect water ageing. J of Dent, 40(12):1134-43.

Hanabusa M, Mine A, Kuboki T. Momoi Y, Van Ende A, 2012. Bonding effectiveness of a new 'multi-mode' adhesive to enamel and dentine. J Dent, 40:475-84.

Marchesi G, Frassetto A, Mazzoni A, Apolonio F, Diolosà M, Cadenaro M, Di Lenarda R, Pashley DH, Tay F, Breschi L, 2014. Adhesive performance of a multi-mode adhesive system: 1-year in vitro study. J Dent, 42(5):603-12.

Mena-Serrano A, Kose C, De Paula EA, 2013. A New Universal Simplified Adhesive: 6-Month Clinical Evaluation. J Esthet Rest Dent, 25:55-69.

Munoz MA, Luque I, Hass V, Reis A, Loguercio AD, Bombarda $\mathrm{NH}$, 2013. Immediate bonding properties of universal adhesives to dentine. J Dent, 41:404-11.

Munoz MA, Sezinando A, Luque-Martinez I, Szesz AL, Reis $A$, Loguercio $A D, 2014$. Influence of a hydrophobic resin coating on the bonding efficacy of three universal adhesives. J Dent, 42:595-602. 
Perdigao J, 2007. New developments in dental adhesion. Dent Clin North Am, 51:333-57.

Perdigao J, Sezinando A, Monteiro PC, 2012. Laboratory bonding ability of a multi-purpose dentin adhesive. Am J Dent, 25:153-8.

Perdigao J, Loguercio AD, 2014. Universal or multi-mode adhesives: why and how? J Adhes Dent, 16:193-4.

Perdigao J, Munoz M, Sezinando A, LuqueMartinez I, Staichak R, Reis A, 2014 (a). Immediate adhesive properties to dentin and enamel of a universal adhesive associated with a hydrophobic resin coat. Oper Dent, 39:489-99.

Perdigao J, Kose C, Mena-Serrano AP, De Paula EA, Tay LY, Reis A, 2014 (b). A new universal simplified adhesive: 18-month clinical evaluation. Oper Dent., 39:113-27.

Perdigao J, Sezinando A, Monteiro PC, 2013. Effect of substrate age and adhesive composition on dentin bonding. Operative Dentistry, 38:267-74.

Pereira GD, Paulillo LA, De Goes MF, Dias CT, 2001. How wet should dentin be? Comparison of methods to remove excess water during moist bonding. J Adhes Dent, 3:257-64.

Peumans M, De Munck J, Van Landuyt K, Poitevin A, Lambrechts P, 2010. Eight-year clinical evaluation of a 2-step self-etch adhesive with and without selective enamel etching. Dent Mater, 26:1176-84.

Peumans M, Kanumilli P, De Munck J, Van Landuyt K, Lambrechts P, Van Meerbeek B, 2005. Clinical effectiveness of contemporary adhesives: a systematic review of current clinical trials. Dent Mater, 21:864-81.

Peşkersoy C, Yıldırım G, Özata F, Önal B, 2013. Üç farklı akışkan kompozitin ve bir kendinden adezivli akışkan kompozitin sınıf $\mathrm{V}$ restorasyonlardaki mikrosızıntı değerlerinin in-vitro olarak incelenmesi. EÜ Diş Hek Fak Derg, 34(2):99-104.

Pleffken PR, de Almeida Lourenco AP, Torres CR, Buhler Borges A, 2011. Influence of application methods of self etching adhesive systems on adhesive bond strength to dentin. J. Adhes. Dent, 13:517-25.

Reis A, Grande RHM, Oliveira GMS, Lopes GC, Loguercio AD, 2007. A 2-year evaluation of moisture on microtensile bond strength and nanoleakage. Dent Mater, 23:862-70.

Sezinando A, 2014. Looking for the ideal adhesivea review. Med Dent Cir Maxilofac, 5(4):194-206.
Takahashi M, Nakajima M, Hosaka K, Ikeda M, Foxton RM, Tagami J, 2011. Long-term evaluation of water sorption and ultimate tensile strength of HEMAcontaining /-free one- step self etch adhezives. $J$ of Dent, 39:506-12.

Tay FR, Gwinnett AJ, Pang KM, Wei SH, 1996. Resin permeation into acid-conditioned, moist, and dry dentin: a paradigm using water-free adhesive primers. J Dent Res, 75:1034-44.

Tay FR, Pashley DH, 2001. Aggressiveness of contemporary self-etching systems I: depth of penetration beyond dentin smear layers. Dent Mater, 17:296-308.

Toledano M, Osorio R, Osorio E, Aguilera FS, Yamauti M, Pashley D, 2007. Durability of resin-dentin bonds; effects of direct/indirect exposure and storage media. Dent Mater, 23: 885-92.

Van Landuyt KL, Mine A, De Munck J, Coutinho E, Peumans $M$, Jaecques $S, 2008$. Technique sensitivity of water-free one-step adhesives. Dent Mater, 24:1258-67.

Van Landuyt KL, Snauwaert J, De munck J, Peumans M, Yoshida Y, Poitevin A, 2007. Systematic review of the chemical composition of contemporary dental adhesives. Biomaterials, 28:3757-85.

Van Meerbeek B, Yoshihara K, Yoshida Y, Mine A, De Munck J, Van Landuyt KL, 2011. State of the art of selfetch adhesives. Dent Mater, 27:17-28.

Woronko GA, Jr., St Germain HA, Jr., Meiers JC, 1996. Effect of dentin primer on the shear bond strength between composite resin and enamel. Oper Dent, 21:116-21.

Yoshida Y, Van Meerbeek B, Nakayama Y, Snauwaert $\mathrm{J}$, Hallemans L, Lambrechts $\mathrm{P}, 2000$. Evidence of chemical bonding at biomaterial-hard tissue interfaces. J Dent Res, 79:709-14.

Yoshida Y, Yoshihara K, Nagaoka N, Hayakawa S, Torii Y, Ogawa T, 2012. Self-assembled nano-layering at the adhesive interface. J Dent Res, 91:376-81.

Yoshihara K, Yoshida Y, Nagaoka N, Fukegawa D, Hayakawa S, Mine A, 2010. Nano-controlled molecular interaction at adhesive interfaces for hard tissue reconstruction. Acta Biomater, 6:3573-82.

\section{Yazışma Adresi:}

\section{Dr.Gülnur Işı TÜRK}

Yüzüncü Yıl Üniversitesi Diş Hekimliği Fakültesi

Restoratif Diş Tedavisi AD

65080 Kampüs, Van

Tel: +90 (555) 3261590

E-mail: isilturk85@gmail.com 